\title{
Effect of Assistive Device for Neck Retraction (ANR) on Neck Muscles during Neck Retraction Exercise
}

\author{
Dong-HYun KIm ${ }^{1)}$, Hun KwON ${ }^{1)}$, Won-GYU YoO $\left.^{2}\right)^{*}$ \\ 1) Department of Physical Therapy, Inje University \\ 2) Department of Physical Therapy, College of Biomedical Science and Engineering, Inje University \\ and Elderly Life Redesign Institute: 607 Obangdong, Gimhae, Gyeongsangnam-do 621-749, Republic \\ of Korea. TEL: +82 55-320-3994, FAX: +82 55-329-1678
}

\begin{abstract}
Purpose] The purpose of present study was to develop an exercise device for assisting neck retraction exercise and to investigate its effectiveness. [Subjects] Fifteen male subjects were recruited. [Methods] The subjects performed the neck retraction exercises with and without assistive device for neck retraction (ANR). EMG activities of the lower cervical erector spinae (LCE), and sternocleidomatoid (SCM) muscles were recorded. [Results] The ANR condition significantly increased LCE activation compared to the control condition. The ANR condition significantly decreased SCM activation compared to the control condition. [Conclusion] We suggest that the ANR condition will help the efficacy of the neck retraction exercise.

Key words: Electromyography, Forward head posture, Neck retraction exercise
\end{abstract}

(This article was submitted Nov. 14, 2012, and was accepted Dec. 16, 2012)

\section{INTRODUCTION}

Recent epidemiological studies indicate that office workers often experience neck and shoulder pain ${ }^{1,2)}$. Although workers with these types of work-related musculoskeletal disorders (WRMSDs) recover with time through rest, the rate of reoccurrence is as high as $60 \%{ }^{2,3)}$. The causes of neck pain include abnormal neck and head posture as well as excessive neck movevment ${ }^{4}$. At the atlanto-occipital joint, an anterior transition of the head, which is defined as a forward head posture (FHP), develops a long moment arm for the cervical extensor (CE) muscles to counteract the load of the head ${ }^{5)}$. This long moment arm generates a low muscular requirement for $\mathrm{CE}$, with greater activation of the upper trapezius, so that weakness in the CE often occurs in patients with a FHP6,7). Conversely, the sternocleidomastoid (SCM) muscle is shortened in FHP ${ }^{5}$. An effective therapeutic exercise for FHP may include neck retraction, for activating the $\mathrm{CE}$ and reducing the SCM. Such an exercise should include extension of the lower and flexion of the upper cervical areas, the opposite of $\mathrm{FHP}^{5}$ ). However, few materials are available for assisting or guiding this type of exercise with respect to direction and resistance. Therefore, the purpose of the present study was to develop an exercise device for assisting neck retraction exercises and to investigate the device's effectiveness.

\footnotetext{
*To whom correspondence should be addressed.

E-mail: won7y@inje.ac.kr
}

\section{SUBJECTS AND METHODS}

The study subjects were 15 males aged $22.7 \pm 2$ years (mean $\pm \mathrm{SD}$ ), with an average height of $174.7 \pm 4.7 \mathrm{~cm}$ and an average body weight of $69.1 \pm 5.7 \mathrm{~kg}$, respectively. None of the subjects had any musculoskeletal disorders or pain in the upper extremities. EMG data were collected by an MP150 system (Biopack System, Santa Barbara, CA, USA). The sampling rate was $1,000 \mathrm{~Hz}$, and the mean of the root mean square value was calculated. Maximal voluntary isometric contraction (MVIC) for each muscle was measured to normalize the EMG signal ${ }^{9)}$. EMG activities of the lower cervical erector spine (LCE) and the sternocleidomatoid (SCM) muscles were recorded. Two bipolar electrodes were attached to the right dominant side of each subject. The present study compared two conditions of neck retraction exercises with and without the assistant device. A newly designed assistant device was used as a neck retraction (ANR) tool. The ANR includes two different types of tubing bands attached to a wooden frame. The upper band provides high resistance at the atlanto-occipital joint, while the lower band provides low resistance at the 4th level of the cervical spine. The ANR is designed to provide direct resistance in the cervical section. The ANR is also designed to provide proper guidance for the neck retraction exercise, and the tubing band support prevents excessive neck extension or flexion. The ANR is constructed of very lightweight wood and weighs a total of $0.7 \mathrm{~kg}$. The subjects used the ANR by placing it on both shoulders and supporting it against a wall. They performed neck retractions while holding the handles with both hands (Fig. 1). The subjects performed the neck retraction exercise, with and without the ANR, for 


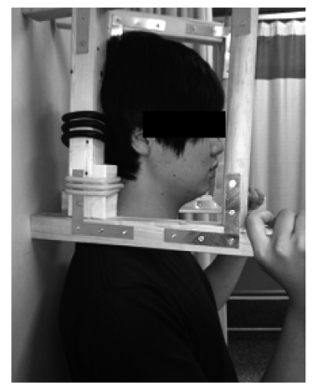

Fig. 1. Assistive Device for Neck Retraction (ANR)

five seconds, retracting their chin until it was in a vertical line with the chest. The paired t-test was conducted to test the differences between the conditions using the SPSS statistical package (version 18.0; SPSS, Chicago, IL, USA). Significance was accepted for values of $p<0.05$.

\section{RESULTS}

The \%MVC of the LCE differed significantly between the conditions. The ANR condition $(47.4 \pm 19.3 \%)$ significantly increased LCE activation compared to the control condition $(14.3 \pm 5.4 \%)(\mathrm{p}<0.05)$. There were significant differences in the \%MVC values of SCM. The ANR condition $(8.3 \pm 4.7 \%)$ significantly decreased SCM activation compared to the control condition $(16.7 \pm 8.3 \%)(p<0.05)$.

\section{DISCUSSION}

Under the ANR condition, there was a significant increase in LCE activation and significantly decrease in SCM activation compared to the control condition. Office workers with neck and shoulder discomfort show a tendency to have a flexed neck posture and low activity of the cervical erector spine muscles ${ }^{6,7)}$. The $\% \mathrm{MVC}$ of LCE was significantly higher in the ANR condition than in the control condition, which was expected since the tubing band provides resistance against neck extension. The neck retraction exercise used in the present study is similar to a previously suggested craniocervical flexion test $(\mathrm{CCFT})^{8)}$. The CCFT examines the endurance of the deep cervical flexors and could be used as a retraining exercise for these muscles. The function of the deep cervical flexors is flexion of the atlanto-occipital joint. Although the deep and superficial cervical flexors both provide the same action in neck flexion, the contractile function of the deep cervical flexors could be interrupted by activation of the superficial neck flexors, such as the SCM, which serves to flex the lower cervical area ${ }^{9)}$. Therefore, we consider that the ANR would help to ensure the effectiveness of neck retraction exercises because of the direct resistance it provides in the cervical section. In addition, most patients are unskilled in neck retraction exercises, so they commonly show excessive movement of the head during these exercises. The ANR provided appropriate guidance in the neck retraction exercise and the tubing bands prevented excessive neck extension or flexion. This study had some limitations as loading in the neck retraction exercise was not controlled. Also, we were unable to show a correlation between the resistance and muscle activity.

\section{ACKNOWLEDGEMENT}

This research was supported by Basic Science Research Program through the National Research Foundation of Korea (NRF) funded by the Ministry of Education, Science and Technology (No. 2012001058).

\section{REFERENCES}

1) Ranasinghe P, Perera YS, Lamabadusuriya DA, et al.: Work related complaints of neck, shoulder and arm among computer office workers: a crosssectional evaluation of prevalence and risk factors in a developing country. Environ Health, 2011, 10: 70. [Medline] [CrossRef]

2) Ijmker S, Huysmans MA, van der Beek AJ, et al.: Software-recorded and self-reported duration of computer use in relation to the onset of severe arm-wrist-hand pain and neck-shoulder pain. Occup Environ Med, 2011, 68: 502-509. [Medline] [CrossRef]

3) Eltayeb SM, Staal JB, Khamis AH, et al.: Symptoms of neck, shoulder, forearms, and hands: a cohort study among computer office workers in Sudan. Clin J Pain, 2011, 27: 275-281. [Medline] [CrossRef]

4) Huisstede BM, Wijnhoven HA, Bierma-Zeinstra SM, et al.: Prevalence and characteristics of complaints of the arm, neck, and/or shoulder (CANS) in the open population. Clin J Pain, 2008, 24: 253-259. [Medline] [CrossRef]

5) Neumann DA: Kinesiology of the musculoskeletal system: foundations for physical rehabilitation. St Louis: Mosby, 2002.

6) Szeto GP, Straker LM, O'Sullivan PB: A comparison of symptomatic and asymptomatic office workers performing monotonous keyboard work-1: neck and shoulder muscle recruitment patterns. Man Ther, 2005, 10: 270280. [Medline] [CrossRef]

7) Szeto GP, Straker LM, O'Sullivan PB: A comparison of symptomatic and asymptomatic office workers performing monotonous keyboard work-2: neck and shoulder kinematics. Man Ther, 2005, 10: 281-291. [Medline] [CrossRef]

8) Jull G, Barrett C, Magee R, et al.: Further clinical clarification of the muscle dysfunction in cervical headache. Cephalalgia, 1999, 19: 179-185. [Medline] [CrossRef]

9) Falla DL, Jull G, Hodges PW: Patients with neck pain demonstrate reduced electromyographic activity of the deep cervical flexor muscles during performance of the craniocervical flexion test. Spine, 2004, 29: 2108-2114. [Medline] [CrossRef] 